\title{
First report of Edwardsiellosis in cage-cultured sharpsnout sea bream, Diplodus puntazzo from the Mediterranean
}

\author{
Pantelis Katharios ${ }^{1 *}$, Constantina Kokkari ${ }^{1}$, Nancy Dourala ${ }^{2}$ and Maria Smyrli ${ }^{1}$
}

\begin{abstract}
Background: Edwardsiella tarda, is a serious bacterial pathogen affecting a broad range of aquaculture fish species. The bacterium has also been reported as a human pathogen, however recent studies have dissociated the fish pathogenic Edwardsiella from those isolated from humans by placing them in a new species, E. piscicida. Here we report the first case of Edwardsiellosis in cultured sharpsnout sea breams, Diplodus puntazzo in Greece.

Case presentation: The disease has affected cultured sharpsnout sea breams of a commercial fish farm in a single location in East Greece. Two populations of sharpsnout sea breams stocked in two consecutive years in floating cages presented signs of disease which included nodules and abscesses in spleen and kidney, morbidity and cumulative mortality reaching $5.3 \%$. Using microbiological, biochemical and molecular tools we have identified Edwardsiella sp. as the main aetiological factor of the disease. Following phylogenetic analysis the bacterial isolates are grouped with the newly described Edwardsiella piscicida species.

Conclusions: This is the first report of Edwardsiellosis in this species but most importantly in sea cage-cultured fish in the Mediterranean which may pose a serious threat for aquaculture fish species in this region.
\end{abstract}

Keywords: Edwardsiella, Bacterial disease, Aquaculture, Fish

\section{Background}

Edwardsiella tarda is a serious bacterial pathogen affecting a wide range of fish species mostly in warm waters [1]. It is a Gram negative, motile bacterium of the Enterobacteriacae family which can be intracellular during infection [2-4] making it less vulnerable to antibiotic treatment [5]. Its importance as a fish pathogen has been gaining increasing interest lately as it is associated with heavy losses in both freshwater and marine cultured fish but also because it can infect humans [6].

The bacterium is responsible for important economic damages in the aquaculture industry of the USA and Asia [5]. In Europe there are few sporadic reports of disease outbreaks in cultured turbot, Scophthalmus maximus (L.) mainly from the Atlantic coast in the Gulf of Biscay [7-9] while in the Mediterranean, E. tarda has been isolated

\footnotetext{
* Correspondence: katharios@hcmr.gr

${ }^{1}$ Institute of Marine Biology, Biotechnology and Aquaculture, Hellenic Centre for Marine Research, Former American Base of Gournes, Heraklion 71003,

Crete, Greece

Full list of author information is available at the end of the article
}

from diseased feral European eels, Anguilla anguilla (L.) from a coastal freshwater lagoon in Spain [10].

Sharpsnout sea bream, Diplodus puntazzo (Walbaum) is a well-appreciated sparid which has been considered for many years as one important candidate for the diversification of the Mediterranean aquaculture. Its production however remains low [11] mostly due to the vulnerability of species to various infectious and non-infectious diseases [12-14].

In this communication we report the isolation and partial characterization of E. tarda from diseased cultured sharpsnout sea breams. To our knowledge, this is the first isolation of the pathogen in Greece and from this host but more importantly the first report of E. tarda from cagecultured marine fish in the Mediterranean.

\section{Case presentation}

The disease has affected cultured sharpsnout sea breams of a commercial fish farm in a single location in East Greece (Saronikos bay). Two populations of sharpsnout sea breams stocked in two consecutive years into 4 
floating cages presented signs of disease. Each cage was stocked with approximately 50-55.000 fish. Two outbreaks of Edwardsiellosis were recorded, the first in October 2013 and the second in July 2014. Table 1 summarizes the production data of the affected stocks and the mortalities observed.

Diseased fish exhibited nodules and abscesses in spleen and kidney (Fig. 1). Pure colonies with identical morphology were obtained at the site by the fish vet of the fish farm in $10 \%$ horse blood Agar (Oxoid) from the kidneys of approximately 30 fish exhibiting signs of distress in each incidence. The initial presumptive diagnosis was performed at the fish farm using API20E bacterial identification kit (BioMerieux, France) on 8-10 pure bacterial colonies from each incidence $(n=18)$. The API profile of all isolates was similar with variability only in the $\mathrm{H}_{2} \mathrm{~S}$ production. Other apparently healthy fish species cultured separately in different cages at the same site of the fish farm including gilthead sea bream, Sparus aurata, European sea bass, Dicentrarchus labrax, meagre, Argyrosomus regius and red porgy, Pagrus pagrus were also sampled ( $n=20$ per fish species) for bacteriological examination (bacterial cultures in blood agar) during the outbreaks and were negative for E. tarda. The fish were treated successfully following oral administration of oxolinic acid in feed (50 $\mathrm{mg} \mathrm{kg}^{-1}$ biomass for 7 consecutive days).

Pure cultures of two strains (EtS1 and EtS2) isolated from sharpsnout sea bream from each two incidences were sent to the laboratories of HCMR for further characterization. Both isolates formed small distinct colonies. The bacteria were characterized and identified biochemically with BIOLOG GEN III and API20E systems according to manufacturers' instruction and molecularly using PCR amplifying Edwardsiella sp. specific gyrB gene coupled with $16 \mathrm{~s}$ sequencing $[15,16]$. The $16 \mathrm{~s}$ rRNA sequence data of the two strains have been deposited in NCBI GenBank under the accession numbers KP729431 and KP729432. In addition, the two strains were screened for the presence of selected virulence genes ( $\operatorname{cit} C$, fimA, $\operatorname{gadB}, k a t B, m u k F$ and $e s r B$ ) with PCR $[17,18]$. All primers used are presented in Table 2.

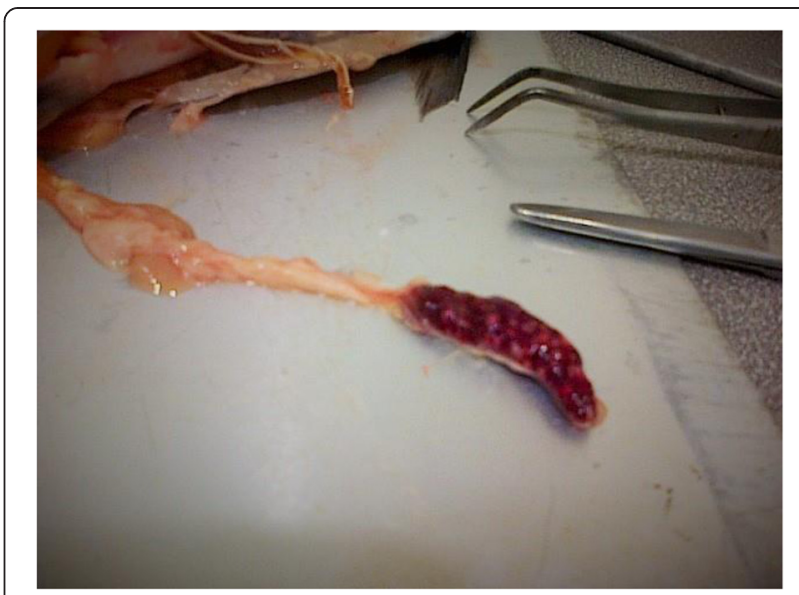

Fig. 1 Nodules in spleen. Enlarged spleen of affected fish with multiple whitish nodules

The isolates were Gram negative, non-motile, oxidase negative, rods, identified as E. tarda with $55 \%$ probability using BIOLOG GENIII. They could utilize several carbon sources such as sugars (maltose, glucose, N-Acetyl-Dglycosamine, N-Acetyl-neuraminic acid, mannose, fructose, glucose-6- $\mathrm{PO}_{4}$, fructose-6- $\mathrm{PO}_{4}$, serine), aminoacids (galacturonic acid, gluconic acid, glucuronic acid) and caroboxylic acid (lactic acid). Both strains could not utilize arabinose, mannitol and sucrose and exhibited variability in $\mathrm{H}_{2} \mathrm{~S}$ production. They could not grow in salinity exceeding $4 \% \mathrm{NaCl}$ and they were resistant in acidic pH. They could grow in 20 and $25{ }^{\circ} \mathrm{C}$ with best growth at $30{ }^{\circ} \mathrm{C}$.

Identification was further validated after amplification of $\operatorname{gyr} B$ gene which resulted in a PCR product at the expected size. All virulence genes assessed were present in the isolates (Fig. 2). Haemolysis was tested on horse and sharpsnout sea bream-blood agar. The later was obtained from disease-free broodstock fish of the Institute of Marine Biology, Biotechnology and Aquaculture, HCMR. Strains E. tarda (DSM 30052) and E. hoshinae (DSM 13771) were used as negative controls and Aeromonas veronii strain (Aero1- HCMR pathogen collection) previously shown to be strongly haemolytic on fish blood

Table 1 Production data and mortalities. Production data of the affected sharpsnout sea breams and mortality observed during the two outbreaks of Edwardsiellosis

\begin{tabular}{|c|c|c|c|c|c|c|}
\hline \multirow[b]{3}{*}{ Cage } & \multirow[b]{3}{*}{$\begin{array}{l}\text { Date } \\
\text { stocked }\end{array}$} & \multirow[b]{3}{*}{$\begin{array}{l}\text { Age at stocking } \\
\text { (months) }\end{array}$} & \multirow{2}{*}{\multicolumn{2}{|c|}{$\begin{array}{l}\text { First outbreak (October 2013) } \\
\text { Water temperature: } 23{ }^{\circ} \mathrm{C}\end{array}$}} & \multirow{2}{*}{\multicolumn{2}{|c|}{$\begin{array}{l}\text { Second outbreak (July 2014) } \\
\text { Water temperature: } 26^{\circ} \mathrm{C}\end{array}$}} \\
\hline & & & & & & \\
\hline & & & $\begin{array}{l}\text { Average weight at first } \\
\text { outbreak }(\mathrm{g})\end{array}$ & $\begin{array}{l}\text { Cumulative } \\
\text { mortality (\%) }\end{array}$ & $\begin{array}{l}\text { Average weight at second } \\
\text { outbreak }(\mathrm{g})\end{array}$ & $\begin{array}{l}\text { Cumulative } \\
\text { mortality (\%) }\end{array}$ \\
\hline 1 & April 2012 & 2 & 323 & 4,82 & 336 & 4,86 \\
\hline 2 & April 2012 & 2 & 319 & 5,30 & 440 & 5,3 \\
\hline 3 & July 2012 & 5 & 292 & 4,76 & 441 & 4,76 \\
\hline 4 & April 2013 & 2 & 84 & 2,23 & 274 & 2,23 \\
\hline
\end{tabular}


Table 2 Primers. List of primers used in this study

\begin{tabular}{|c|c|c|c|c|}
\hline Gene & & Primer's sequence & $\begin{array}{l}\text { Size } \\
\text { (bp) }\end{array}$ & Reference \\
\hline \multirow[t]{2}{*}{ gyrB } & $\mathrm{F}$ & 5'- GCATGGAGACCTTCAGCAAT-3' & 415 & {$[15]$} \\
\hline & $\mathrm{R}$ & 5'-GCGGAGATTITGCTCTTCTT-3' & & \\
\hline \multirow[t]{2}{*}{$\operatorname{gadB}$} & $\mathrm{F}$ & 5'- ATTTGGATTCCCGCTTTGGT-3' & 583 & [30] \\
\hline & $\mathrm{R}$ & 5'- GCACGACGCCGATGGTGTTC-3' & & \\
\hline \multirow[t]{2}{*}{ mukF } & $\mathrm{F}$ & 5'- TTGCTGGCTATCGCTACCCT-3' & 357 & {$[30]$} \\
\hline & $\mathrm{R}$ & 5'- AACTCATCGCCGCCCTCTTC-3' & & \\
\hline \multirow[t]{2}{*}{ citC } & $\mathrm{F}$ & 5'- TTTCCGTTGTGAATCAGGTC-3' & 596 & {$[30]$} \\
\hline & $\mathrm{R}$ & 5'- AATGTTTCGGCATAGCGTTG-3' & & \\
\hline \multirow[t]{2}{*}{$\operatorname{fimA}$} & $\mathrm{F}$ & 5'- CTGTGAGTGGTCAGGCAAGC-3' & 441 & {$[30]$} \\
\hline & $\mathrm{R}$ & 5'- TAACCGTGTTGGCGTAAGAGC-3' & & \\
\hline \multirow[t]{2}{*}{ esr $\mathrm{B}$} & $\mathrm{F}$ & 5'-TCGTTGAAGATCATGCCTTGC-3' & 311 & {$[30]$} \\
\hline & $\mathrm{R}$ & 5'-TGCTGCGGGCTTTGCTT-3' & & \\
\hline \multirow[t]{2}{*}{ katB } & $\mathrm{F}$ & 5'-CTTAGCCATCAGCCCTTCC-3' & 1417 & {$[30]$} \\
\hline & $\mathrm{R}$ & 5'-GCGAGTGCCGTAGTCCTT-3' & & \\
\hline \multirow[t]{2}{*}{$16 \mathrm{~s}$ rRNA } & $27 f$ & 5'-AGAGTTTGATCMTGGCTCAG-3' & 1465 & {$[16]$} \\
\hline & $1492 r$ & 5'-CGGTTACCTTGTTACGACTT -3' & & \\
\hline
\end{tabular}

as positive control. Following $48 \mathrm{~h}$ incubation at $25{ }^{\circ} \mathrm{C}$ only the Aeromonas veronii control strain was positive for haemolysis.

Antibiotic susceptibility of the two isolates was determined with a disk diffusion method [19] on MuellerHinton agar for ampicillin $(10 \mu \mathrm{g})$, oxytetracycline $(30 \mu \mathrm{g})$, oxolinic acid $(2 \mu \mathrm{g})$, flumequine $(30 \mu \mathrm{g})$, florfenicol $(30 \mu \mathrm{g})$ and sulphamethoxazole/trimethoprim $(25 \mu \mathrm{g})$ as suggested for fish pathogens [20]. Inhibition diameter was recorded after $24 \mathrm{~h}$ incubation at $25^{\circ} \mathrm{C}$. Response was determined according to the breakpoints shown in Table 3.

Phylogenetic relationships of the two isolates were studied using $16 \mathrm{~s}$ rRNA gene. The taxonomic status, strain collection numbers and GenBank Accession numbers (http://www.ncbi.nlm.nih.gov/) of all used sequences are

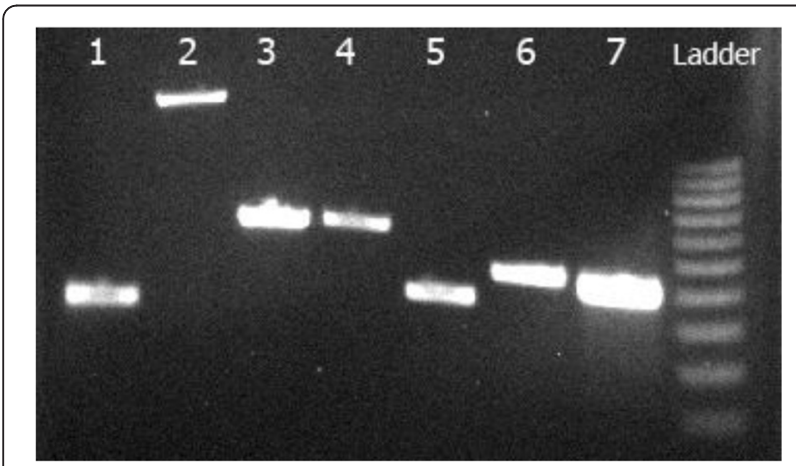

Fig. 2 Virulence genes. PCR amplification of selected virulence genes for EtS1. Lanes 1-7: esrB, katB, gadB, citC, mukF, fimA, gyrB presented in Table 4. A total length of 721 bp sequences was used for the phylogenetic analyses. Genetic distances and Neighbor-joining analysis [21] were respectively estimated and performed in MEGA [22] under Tamura-Nei [23] model of evolution. Confidence of tree nodes was tested by bootstrap analyses with 1000 replicates. Both isolates were grouped with E. ictaluri and E. tarda strains isolated from fish (Fig. 3). Genetic distances between strains EtS1 and EtS2 was $0 \%$, while the mean genetic distance within the fish-clade was $0.002 \%$ and overall mean distance for the genus was $0.005 \%$.

\section{Discussion}

This is the first report of Edwardsiellosis in aquaculture fish in Greece and one of the few in the Mediterranean. Edwardsiella tarda has been isolated from feral European eels, Anguilla anguilla from a coastal freshwater lagoon near Valencia in Spain very close to the Mediterranean Sea [10]. In addition, Edwardsiellosis has also been reported in the Mediterranean coast of Spain in cultured European seabass, Dicentrarchus labrax, with the bacterial isolate however resembling E. ictaluri [24]. Recently, the assignment of the fish pathogenic isolates to this species has been questioned by Abayneh et al. (2013) [25] who instead proposed a new species, E. piscicida. The phylogenetic analysis of the current stains indicate that they are indeed grouped with the strains isolated from other fish. Moreover the biochemical profile of the two isolates is consistent with the profile of E. piscicida type strain [25] with the exception of motility. Atypical non-motile virulent E. tarda have been isolated from marine fish in Japan [26]. Those strains however were able to utilize arabinose and mannitol unlike the strains described in the current study. Recently, atypical non-motile E. tarda strains affecting cultured turbot in China were described [27]. These strains were similar to those described in the current study since besides being non-motile they could also utilize mannose and fructose but not arabinose and mannitol. Whether the strains described herein are E. piscicida instead of E. tarda needs further investigation since taxonomy of the Edwardsiella genus has not yet been fully resolved. Edwardsiellosis is manifested as a typical acute bacterial septicaemia with external heamorrhages and petechiae in skin and fins and bloody ascites in the peritoneal cavity with liver, spleen and kidney congestions [1, 28]; however it is also associated with more sub-acute lesions such as abscesses and nodules in the visceral organs [8] as in this case. The impact of the disease and its manifestation in terms of external clinical signs may vary depending on fish species. Disease outbreaks occur at high water temperatures $[1,27]$ usually above $20{ }^{\circ} \mathrm{C}$ which is in accordance to the water temperature occurring during the disease outbreaks reported here. Mortality can be severe and is dependent on many different factors such as fish 
Table 3 Antiobiotic sensitivity. Sensitivity of the two Edwardsiella isolates against the antibiotics commonly used in aquaculture (r: radius, S: sensitive, I: intermediate, R: resistant)

\begin{tabular}{|c|c|c|c|c|c|c|c|}
\hline \multirow[b]{2}{*}{ Antibiotic } & \multicolumn{3}{|c|}{ Sensitivity breakpoints (mm) } & \multicolumn{2}{|c|}{ Radius (mm) } & \multicolumn{2}{|c|}{ Sensitivity } \\
\hline & Resistant & Intermediate & Sensitive & EtS1 & EtS2 & EtS1 & EtS2 \\
\hline SFT $(25 \mu \mathrm{g})$ & $r<14$ & $14 \leq r \leq 16$ & $r>16$ & $16-17$ & $12-13$ & $S$ & $\mathrm{R}$ \\
\hline OXA $(2 \mu \mathrm{g})$ & $r<11$ & $11 \leq r \leq 13$ & $r>13$ & $18-19$ & $18-20$ & $\mathrm{~S}$ & $\mathrm{~S}$ \\
\hline FLO $(30 \mu \mathrm{g})$ & $r<16$ & $16 \leq r \leq 18$ & $r>18$ & 19-21 & $20-22$ & S & $\mathrm{S}$ \\
\hline OTC $(30 \mu \mathrm{g})$ & $r<15$ & $15 \leq r \leq 18$ & $r>18$ & $15-17$ & $17-18$ & । & I \\
\hline FLU $(30 \mu g)$ & $r<16$ & $16 \leq r \leq 19$ & $r>19$ & 17 & 22 & 1 & $\mathrm{~S}$ \\
\hline AMP $(10 \mu g)$ & $r<14$ & $14 \leq r \leq 18$ & $r>18$ & 10 & $12-14$ & $\mathrm{R}$ & $\mathrm{R}$ \\
\hline
\end{tabular}

species, age, environmental conditions, handling, stress etc. Host specificity seemed to be an important factor since of the four different species cultured at the specific fish farm only sharpsnout sea bream was affected. The two strains described in this study showed differences in the antiobiotic sensitivity. EtS2 which was isolated at the second incidence was resistant to the potentiated sulfonamide SFT unlike EtS1 which was isolated at the first incidence, while both strains were resistant to ampicillin and sensitive to oxolinic acid and florfenicol. Antibiotic resistance is one of the greatest concerns in aquaculture and Edwardsiella tarda isolated from fish has shown that can be multi-drug resistant including resistance to trimethoprime and ampicillin [29]. Virulence of the Edwardsiella sp. isolates was not assessed based on in vivo experiments due to legal and ethical constraints concerning the use of animals but on their virulent gene repertoire. The current isolates contained the main virulent genes described in literature after thorough functional genomic analysis and screening of virulent and a-virulent E. tarda strains [17]. Those genes are implicated in virulence by either providing resistance to the bacterium

Table 4 Bacterial strains and codes. Taxonomy, collection codes and accession numbers from NCBI GenBank of the bacterial strains used in this study

\begin{tabular}{|c|c|c|c|c|}
\hline Strain & Species & Host/source & Geographic origin & Sequence code \\
\hline ET883 & E. piscicida & European eel (Anguilla anguilla) & Greaker, Norway (1989) & NR125649 \\
\hline RM 298.1 & E. piscicida & Turbot (Scophthalmus maximus) & Southern Europe (2006) & KC138730 \\
\hline HL 9.1 & E. piscicida & Turbot (Scophthalmus maximus) & Northern Europe (2006) & KC138727 \\
\hline ETA1 & E. piscicida & Turbot (Scophthalmus maximus) & Scotland, UK (2007) & KC138724 \\
\hline ETK01 & E. piscicida & Korean catfish (Silurus asotus) & Jeollabukdo, South Korea (2008) & KC138726 \\
\hline NCIMB 2056 & E. piscicida & Sea bream (Evynnis japonicas) & NCIMB collection & KC138729 \\
\hline LTB4 & E. tarda & Turbot (Scophthalmus maximus) & Qingdao, China (2006) & EU259315 \\
\hline NCIMB 2034 & E. tarda & Unknown fish spp. & NCIMB collection & KC138728 \\
\hline ET080813 & E. tarda & Marbled eel (Anguilla marmorata) & Qingdao, China (2008) & CP006664 \\
\hline ET080814 & E. tarda & Japanese eel (Anguilla japonica) & Qingdao, China (2008) & KC138723 \\
\hline ATCC $15947^{\top}$ & E. tarda & Human faeces & Kentucky, USA (1959) & NR024770 \\
\hline ATCC 23685 & E. tarda & Human faeces & & 294638553 \\
\hline AL93 & E. ictaluri & Channel catfish (Ictalurus punctatus) & USA & KC138721 \\
\hline ATCC $33202^{\top}$ & E. ictaluri & Channel catfish (Ictalurus punctatus) & Georgia, USA (1976) & NR024769 \\
\hline LH51 & E. ictaluri & Channel catfish (Ictalurus punctatus) & Liaoning, China & EU541494 \\
\hline $93-146$ & E. ictaluri & Channel catfish (Ictalurus punctatus) & USA & CP001600.2 \\
\hline ATCC $33379^{\top}$ & E. hoshinae & Female puffin (Fratercula arctica) & France & AB682272 \\
\hline EtS1 & Edwardsiella sp. & Sharpsnout sea bream (Diplodus puntazzo) & Greece (2013) & KP729431 \\
\hline EtS2 & Edwardsiella sp. & Sharpsnout sea bream (Diplodus puntazzo) & Greece (2014) & KP729432 \\
\hline $2457^{\top}$ & Shigella flexneri & & & AE014073 \\
\hline 568 & Serratia proteamaculans & & & NR074820 \\
\hline
\end{tabular}




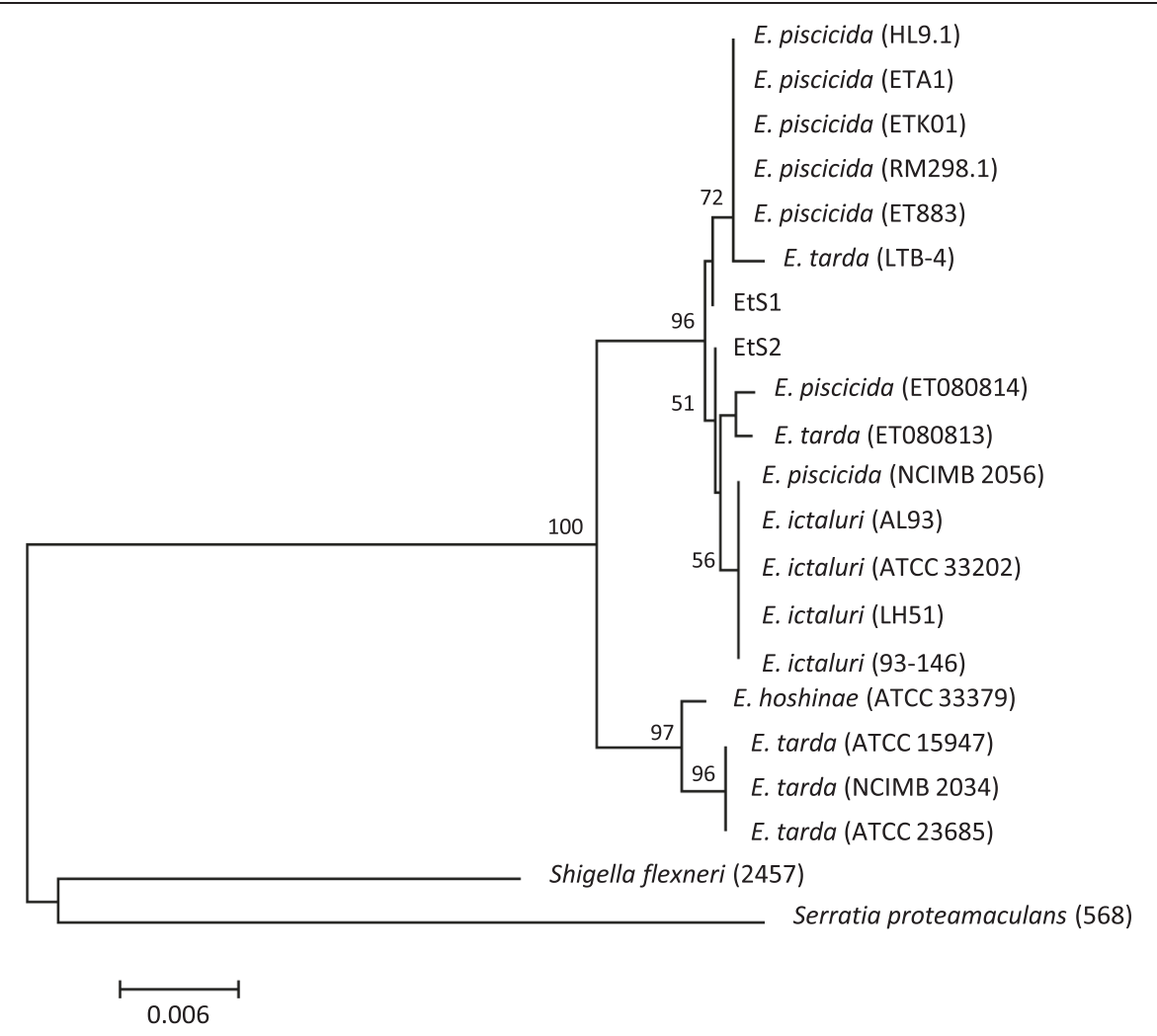

Fig. 3 Phylogenetic analysis. Phylogenetic relationships of Edwardsiella strains studied as derived from Neighbour-Joining analysis for 165 gene. Numbers on clades indicate the bootstrap values

against host phagocyte killing activity (GadB, KatB) [17] indicating also ability for intracellular survival and replication which has been shown for this species [4], or providing the necessary tools for cell adhesion (fimA) [17] and penetration (esrB which encodes a regulator protein for type III secretion system) [18]. The presence of these genes together with the clinical signs of the disease and the absence of any other pathogen suggest that Edwardsiella sp. was the aetiological cause of the disease.

\section{Conclusions}

Edwardsiella sp. was isolated from diseased cultured sharpsnout sea bream. It is the first report in this host but also the first report from cultured fish in the Mediterranean. The isolates, identified as E. tarda are phylogenetically closer to the newly described E. piscicida species. Although confined only to this species until now, the pathogen could potentially spread in other species and pose serious threat to the Mediterranean aquaculture industry.

\section{Availability of supporting data}

The data set supporting the results of this article is included within the article (See Table 4).

\section{Abbreviations}

HCMR: Hellenic Centre for Marine Research; SFT: sulphamethoxazole/ trimethoprim; OXA: oxolinic acid; FLO: florfenicol; OTC: oxytetracycline; FLU: flumequine; AMP: ampicillin.

\section{Competing interests}

The authors declare that they have no competing interests.

\section{Authors' contributions}

PK participated in the design of the study, coordinated the work and drafted the manuscript, CK performed the analytical work, participated in the design of the study and helped to draft the manuscript, ND examined the diseased fish, isolated the strains and performed the initial identification on site and MS performed the phylogenetic analysis and helped to draft the manuscript. All authors have read and approved the final manuscript.

\section{Authors' information}

PK is a researcher at the Institute of Marine Biology, Biotechnology and Aquaculture of the Hellenic Centre for Marine Research (IMBBA-HCMR), Crete, Greece, CK and MS are biologists and technical scientists at IMBBA-HCMR and ND is a veterinarian at Selonda Aquaculture SA.

\section{Acknowledgements}

This work has been financially supported by the FISHPHAGE (131), Excellence Program, National Strategic Reference Framework 2007-2013 co-funded by the European Social Fund and National Resources.

\section{Author details}

'Institute of Marine Biology, Biotechnology and Aquaculture, Hellenic Centre for Marine Research, Former American Base of Gournes, Heraklion 71003, Crete, Greece. ${ }^{2}$ Selonda Aquaculture, Navarhou Nikodimou 30, 10556 Athens, Greece. 
Received: 26 February 2015 Accepted: 14 July 2015

Published online: 21 July 2015

\section{References}

1. Bin PS, Aoki T, Jung TS. Pathogenesis of and strategies for preventing Edwardsiella tarda infection in fish. Vet Res. 2012:43:67.

2. $\quad$ Ling SHM, Wang XH, Lim TM, Leung KY. Green fluorescent protein-tagged Edwardsiella tarda reveals portal of entry in fish. FEMS Microbiol Lett. 2001;194:239-43.

3. Janda JM, Abbott SL, Kroske-Bystrom S, Cheung WKW, Powers C, Kokka RP et al. Pathogenic properties of Edwardsiella species. J Clin Microbiol. 1991;29:1997-2001.

4. Okuda J, Takeuchi Y, Nakai T. Type III secretion system genes of Edwardsiella tarda associated with intracellular replication and virulence in zebrafish. Dis Aquat Organ. 2014;111:31-9.

5. Xu T, Zhang $\mathrm{X}-\mathrm{H}$. Edwardsiella tarda: an intriguing problem in aquaculture. Aquaculture. 2014;431:129-35.

6. Taguchi H, Tamai T, Numata M, Maeda H, Ohshige A, Iwaya H, et al. Endoscopic ultrasonography-guided transmural drainage of an infected hepatic cyst due to Edwardsiella tarda: a case report. Clin J Gastroenterol. 2014;7:422-8.

7. Nougayrede PH, Vuillaume A, Vigneulle M, Faivre B, Luengo S, Delprat J. First isolation of Edwardsiella tarda from diseased turbot (Scophthalmus maximus) reared in a sea farm in the bay of biscay. Bull Eur Assoc Fish Pathol. 1994;14:128-9.

8. Padrós F, Zarza C, Dopazo L, Cuadrado M, Crespo S. Pathology of Edwardsiella tarda infection in turbot, Scophthalmus maximus (L.). J Fish Dis. 2006:29:87-94.

9. Castro N, Toranzo AE, Barja JL, Núñez S, Magariños B. Characterization of Edwardsiella tarda strains isolated from turbot, Psetta maxima (L.). J Fish Dis. 2006;29:541-7.

10. Alcaide $\mathrm{E}$, Herraiz S, Esteve C. Occurrence of Edwardsiella tarda in wild European eels Anguilla anguilla from Mediterranean Spain. Dis Aquat Organ. 2006;73:77-81.

11. Basurco B, Lovatelli A, García B. Current status of Sparidae aquaculture. Sparidae: biology and aquaculture of Gilthead Sea Bream and other species. 2011;1-50

12. Katharios P, Papadaki M, Ternengo S, Kantham PK, Zeri C, Petraki PE, et al. Chronic ulcerative dermatopathy in cultured marine fishes. Comparative study in sharpsnout sea bream, Diplodus puntazzo (Walbaum). J Fish Dis. 2011;34:459-74.

13. Katharios P, Papadaki M, Papandroulakis N, Divanach P. Severe mortality in mesocosm-reared sharpsnout sea bream Diplodus puntazzo larvae due to epitheliocystis infection. Dis Aquat Organ. 2008:82:55-60.

14. Athanassopoulou F, Prapas T, Rodger H. Diseases of Puntazzo puntazzo Cuvier in marine aquaculture systems in Greece. J Fish Dis. 1999;22:215-8.

15. Lan J, Zhang XH, Wang Y, Chen J, Han Y. Isolation of an unusual strain of Edwardsiella tarda from turbot and establish a PCR detection technique with the gyrB gene. J Appl Microbiol. 2008;105:644-51.

16. Lane DS. 165 and $23 S$ rRNA sequencing. In: Nucleic Acid Techniques in Bacterial Systematics. 1990. p. 115-75.

17. Srinivasa Rao PS, Lim TM, Leung KY. Functional Genomics Approach to the Identification of Virulence Genes Involved in Edwardsiella tarda Pathogenesis. Infect Immun. 2003;71:1343-51.

18. Tan YP, Zheng J, Tung SL, Rosenshine I, Leung KY. Role of type III secretion in Edwardsiella tarda virulence. Microbiology. 2005;151:2301-13.

19. Bauer AW, Kirby WM, Sherris JC, Turck M. Antibiotic susceptibility testing by a standardized single disk method. Am J Clin Pathol. 1966;45:493-6.

20. Alderman DJ, Smith P. Development of draft protocols of standard reference methods for antimicrobial agent susceptibility testing of bacteria associated with fish diseases. Aquaculture. 2001;196:211-43.

21. Saitou N, Nei M. The neighbor-joining method: a new method for reconstructing phylogenetic trees. Mol Biol Evol. 1987;4:406-25.

22. Tamura K, Peterson D, Peterson N, Stecher G, Nei M, Kumar S. MEGA5: molecular evolutionary genetics analysis using maximum likelihood, evolutionary distance, and maximum parsimony methods. Mol Biol Evol. 2011;28:2731-9.

23. Tamura K, Nei M. Estimation of the number of nucleotide substitutions in the control region of mitochondrial DNA in humans and chimpanzees. Mol Biol Evol. 1993;10:512-26.
24. Blanch AR, Pinto RM, Jofre JT. Isolation and characterization of an Edwardsiella sp. strain, causative agent of mortalities in sea bass (Dicentrarchus labrax). Aquaculture. 1990;88:213-22.

25. Abayneh T, Colquhoun DJ, Sørum H. Edwardsiella piscicida sp. nov., a nove species pathogenic to fish. J Appl Microbiol. 2013;114:644-54.

26. Matsuyama T, Kamaishi T, Ooseko N, Kurohara K, lida T. Pathogenicity of motile and non-motile Edwardsiella tarda to some marine fish. Fish Pathol. 2005:40:133-6.

27. Qin L, Xu J, Wang YG. Edwardsiellosis in farmed turbot, Scophthalmus maximus (L.), associated with an unusual variant of Edwardsiella tarda: a clinical, aetiological and histopathological study. J Fish Dis. 2014;37:103-11.

28. Shetty M, Maiti B, Venugopal MN, Karunasagar I. First isolation and characterization of Edwardsiella tarda from diseased striped catfish Pangasianodon hypophthalmus (Sauvage). J Fish Dis. 2014;37:265-71.

29. Acharya M, Maiti NK, Mohanty S, Mishra P, Samanta M. Genotyping of Edwardsiella tarda isolated from freshwater fish culture system. Comp Immunol Microbiol Infect Dis. 2007;30:33-40.

30. Wang X, Yan M, Wang Q, Ding L, Li F. Identification of Edwardsiella tarda isolated from duck and virulence genes detection. African J Microbiol Res. 2012;6:4970-5.

\section{Submit your next manuscript to BioMed Central and take full advantage of:}

- Convenient online submission

- Thorough peer review

- No space constraints or color figure charges

- Immediate publication on acceptance

- Inclusion in PubMed, CAS, Scopus and Google Scholar

- Research which is freely available for redistribution 